\title{
Sensitivity and specificity of the Brazilian version of the Montreal Cognitive Assessment - Basic (MoCA-B) in chronic kidney disease
}

\author{
Sensibilidade e especificidade da versão brasileira do Montreal Cognitive \\ Assessment - Basic (MoCA-B) na doença renal crônica
}

Thaís Malucelli Amatneeks, ${ }^{1,2}$ (D) Amer Cavalheiro Hamdan² (D)

\begin{abstract}
Introduction: Cognitive impairment in chronic kidney disease (CKD) is commonly associated with neuropsychiatric disorders. As a complex pathology, at all stages of CKD patients need to have a good understanding of the need for drug and nutritional adherence. Cognitive screening is the starting point for detection of cognitive impairments.

Objective: To determine the specificity and sensitivity of the Brazilian Portuguese version of the Montreal Cognitive Assessment - Basic (MoCA-B) for identification of cognitive impairment in the CKD population.

Methods: This was a cross-sectional study with 163 CKD patients undergoing hemodialysis treatment. The Mini-Mental State Examination (MMSE) and MoCA-B were administered.

Results: The MoCA-B has reliable internal consistency (Cronbach's alpha $=0.74$ ). A cutoff point of $\leq 21$ points provides the best sensitivity and specificity for detection of cognitive impairment. The education variable had less impact on the total MoCA-B score than on the total MMSE score.

Conclusions: The MoCA-B is a suitable screening instrument for evaluating the global cognition of hemodialysis patients. The results can help health professionals to conduct evaluations and plan clinical management.
\end{abstract}

Keywords: Mental status and dementia tests, psychometrics, kidney diseases, neuropsychological tests.

\section{Resumo}

Introdução: $O$ comprometimento cognitivo na doença renal crônica (DRC) é comumente associado a distúrbios neuropsiquiátricos. Sendo uma patologia complexa, a DRC, em qualquer estágio, requer que o paciente tenha uma boa compreensão da necessidade de adesão ao medicamento e à nutrição. A triagem cognitiva é o ponto de partida para a deteç̧ão de deficiências cognitivas.

Objetivo: Determinar a especificidade e a sensibilidade da versão em português do Brasil do Montreal Cognitive Assessment - Basic (MoCA-B) para identificação de comprometimento cognitivo na população com DRC.

Métodos: Este foi um estudo transversal com 163 pacientes com DRC em tratamento hemodialítico. Foram aplicados o Mini Exame do Estado Mental (MEEM) e o MoCA-B.

Resultados: O MoCA-B obteve consistência interna confiável (alfa de Cronbach $=0,74$ ). Um ponto de corte de $\leq 21$ pontos fornece a melhor sensibilidade e especificidade para a deteç̧ão de comprometimento cognitivo. A variável educação teve menos impacto no escore total do MoCA-B do que no escore total do MEEM.

Conclusões: O MoCA-B é um instrumento de triagem adequado para avaliar a cognição global de pacientes em hemodiálise. Os resultados podem ajudar os profissionais de saúde a realizar avaliações e planejar o manejo clínico.

Descritores: Testes de estado mental e demência, psicometria, doença renal, testes neuropsicológicos.

\footnotetext{
${ }^{1}$ Fundação Pró-Renal, Curitiba, PR, Brazil. ${ }^{2}$ Universidade Federal do Paraná, Curitiba, PR, Brazil. Submitted Oct 12 2018, accepted for publication Mar 022019.

Suggested citation: Amatneeks TM, Hamdan AC. Sensitivity and specificity of the Brazilian version of the Montreal Cognitive Assessment - Basic (MoCA-B) in chronic kidney disease. Trends Psychiatry Psychother. 2019;41(4):327-333. http://dx.doi.org/10.1590/2237-6089-2018-0085
} 


\section{Introduction}

Cognitive impairment in chronic kidney disease (CKD) is commonly associated with neuropsychiatric disorders such as depression, delirium, and dementia. ${ }^{1}$ It is believed that identification of cognitive deficits in chronic patients may have a positive impact on the prognosis of treatment. Timely intervention can modify the course of the disease, ${ }^{2}$ since a patient with cognitive impairment may have poor adherence to medication and treatment, and may have malnutrition, reduced quality of life, increased care costs, and early mortality. ${ }^{3}$

Chronic kidney disease is a complex pathology and so at all stages patients must understand the need for adherence to drug prescriptions and nutritional advice. Although cognitive impairment among these patients is recognized in the literature, it is underdiagnosed in the clinical context and is often perceived as resistance to therapeutic adherence. While no medical intervention currently available can reverse the progression of dementia-related degenerative disorders, it is believed that early identification of cognitive decline may modify the impact of these disorders on cognition and on patient's lack of autonomy. ${ }^{2}$

Cognitive screening is the starting point for detection of cognitive impairments, dementia, and other neuropsychiatric syndromes, constituting an important public and clinical health initiative. A relatively small number of short cognitive screening instruments are used by most clinicians and in some cases their efficacy is unknown. ${ }^{4}$ The Montreal Cognitive Assessment (MoCA) is a short cognitive screening tool with high sensitivity and specificity for detection of mild cognitive impairment. It is a test with an average administration time of 10 minutes that covers important cognitive domains, such as attention and concentration, executive functions, memory, language, visual-constructive skills, conceptualization, calculation, and orientation. ${ }^{5}$

This evaluation, created by Nasreddinne et al., ${ }^{5}$ demonstrated excellent test-retest reliability and predictive values for mild cognitive impairment and Alzheimer's disease. Due to the structure of the test, it is feasible for use in clinical settings in which the time available for evaluation is often limited. The original version is a screening tool recommended for people with at least 4 years of schooling. However, an adaptation for Brazilian Portuguese obtained internal consistency too low to be considered sufficient for validation of the test in this language. 6

The Montreal Cognitive Assessment - Basic (MoCA-B) was created with the objective of testing people who were illiterate or had less than five years of schooling. ${ }^{7}$ The Brazilian version was adapted by Daniel Apolinario and is available on mocatest.org. Due to the predominance of low schooling among renal patients in Brazil, this instrument may be more appropriate for administration in this context. There is recent interest in the literature in identifying cut-off criteria for different populations. ${ }^{8,9}$ However, there are no published studies on cut-off criteria or issues related to the psychometric properties of the Brazilian version of the MoCA-B. Thus, the aim of this study was to determine the specificity and sensitivity of the Brazilian Portuguese version of the MoCA-B for identification of cognitive impairment in the CKD population.

\section{Method}

This is a cross-sectional study approved by the health ethics committee at the Universidade Federal do Paraná, Brazil (CAAE: 69700717.7.0000.0102). All participants signed the informed consent form before participating. The participants who administrate the tests were trained in the same way by the main researchers. They had had no contact with demographic and health information prior to administrating the survey.

\section{Participants}

The study sample consisted of 163 patients with Chronic Renal Disease, recruited by convenience and assessed between January and August of 2018. Patients who met the eligibility criteria were actively enrolled at any of three selected hemodialysis clinics in the city of Curitiba, PR, Brazil. The eligibility criteria were: age over 18 years; and absence of any significant hearing or visual impairments that would prevent administration of the cognitive assessment tool.

\section{Instruments}

Three instruments were used for evaluation of participants, as described below.

\section{Sociodemographic questionnaire}

An instrument covering identification information (age, sex, schooling), clinical data (time on treatment, disease etiology, comorbidities, previous treatments, prior history of stroke, vascular access, use of psychoactive drugs), and the Brazilian Economic Classification Criteria.

\section{Mini-Mental State Examination (MMSE)}

This was used as a gold standard measure for identification of cognitive impairment. An adaptation by Duncan et al. was used. ${ }^{10}$ 
Montreal Cognitive Assessment - Basic (MoCA-B)

This is a 30-point test that evaluates six cognitive domains: visual perception, executive functioning, language, attention, memory, and orientation. ${ }^{7}$ The Brazilian Portuguese version was adapted by Daniel Apolinario and is freely available for clinical use (www. mocatest.org, see the Basic section). The English language version of the test considers a score $<24$ as identifying cognitive impairment. There are no studies of the Brazilian Portuguese version that indicate a score for reference.

\section{Data analysis}

Descriptive analysis of the data was performed (mean, standard deviation, absolute frequency, and relative frequency). Inferential analysis was performed using analysis of variance (ANOVA) with the Bonferroni post-hoc test. Cohen's index was used to calculate the effect size between means. Multiple and Simple Regression Analysis was performed using the total scores for the instruments as dependent variables and age and schooling as independent variables. The receiver operating characteristic (ROC) curve was used to establish the instrument's sensitivity and specificity, analyzing the area under the curve (AUC) and the Youden Index. Cronbach's alpha was measured on standardized items to assess the internal consistency of MoCA-B. The level of significance for rejection of the null hypothesis was $a<0.05$. Statistical analyses were performed using the Statistical Package for the Social Sciences (SPSS) version 23. MedCalc software was used to assist in analysis of the ROC curve and the Youden index. The University of Colorado Virtual Calculator was used for effect size calculations (https:// www. uccs.edu/ lbecker/).

\section{Results}

All participants in the sample were at chronic renal disease stage 5 , with glomerular filtration rate (GFR) of $15 \mathrm{ml} / \mathrm{min}$ or less, and were on hemodialysis. Table 1 shows the sociodemographic and clinical characteristics of the sample. The data shown are age, time on dialysis, sex, schooling, and disease etiology.

The sample was predominantly male, and the prevailing educational level category was up to 5 years of schooling. The large variance among participants in relation to time since starting treatment is noteworthy. With regard to CKD etiology, the category "others" encompasses patients who had indefinite etiology recorded on their medical records as well as one case of Lupus Nephritis. Although there was a fair degree of variation in disease etiology in this sample, analysis of comorbidities revealed that $77.9 \%$ of the sample had systemic arterial hypertension and $30.7 \%$ had diabetes mellitus. Only 10 patients (6.1\%) had comorbid Hepatitis C and 2 (1.2\%) had HIV.

Table 1 - Sociodemographic and clinical data

\begin{tabular}{|c|c|c|c|c|c|}
\hline & Mean & SD & Min & & Max \\
\hline Age & 54.40 & 14.78 & 19 & & 83 \\
\hline Time on dialysis (months) & 49.02 & 56.41 & 0.01 & & 329 \\
\hline & \multicolumn{2}{|c|}{$\mathbf{n}$} & \multicolumn{3}{|c|}{$\%$} \\
\hline \multicolumn{6}{|l|}{ Sex } \\
\hline Male & \multicolumn{2}{|c|}{107} & \multicolumn{3}{|c|}{65.64} \\
\hline Female & \multicolumn{2}{|c|}{56} & \multicolumn{3}{|c|}{34.36} \\
\hline \multicolumn{6}{|l|}{ Schooling } \\
\hline Illiterate & \multicolumn{2}{|c|}{11} & \multicolumn{3}{|c|}{6.75} \\
\hline $1-5$ years & \multicolumn{2}{|c|}{53} & \multicolumn{3}{|c|}{32.52} \\
\hline $6-11$ years & \multicolumn{2}{|c|}{49} & \multicolumn{3}{|c|}{30.06} \\
\hline$\geq 12$ years & \multicolumn{2}{|c|}{50} & \multicolumn{3}{|c|}{30.67} \\
\hline \multicolumn{6}{|l|}{ Etiology } \\
\hline Polycystic kidney disease & \multicolumn{2}{|c|}{11} & \multicolumn{3}{|c|}{6.7} \\
\hline Chronic glomerulonephritis & \multicolumn{2}{|c|}{39} & \multicolumn{3}{|c|}{23.9} \\
\hline Diabetic nephropathy & \multicolumn{2}{|c|}{37} & \multicolumn{3}{|c|}{22.7} \\
\hline Hypertensive nephropathy & \multicolumn{2}{|c|}{43} & \multicolumn{3}{|c|}{26.4} \\
\hline Chronic interstitial nephritis & \multicolumn{2}{|c|}{14} & \multicolumn{3}{|c|}{8.6} \\
\hline Others & \multicolumn{2}{|c|}{19} & \multicolumn{3}{|c|}{$\begin{array}{c}8.0 \\
11.7\end{array}$} \\
\hline
\end{tabular}

Max = maximum; Min = minimum; SD = standard deviation. 
Analysis of the internal consistency of the MoCA-B was performed, because there are no published articles on the version adapted for Brazilian Portuguese that report its reliability. The result obtained was considered acceptable, with Cronbach's alpha of 0.74.

Table 2 shows the mean, standard deviation, minimum, and maximum score for each component of the MoCA-B.

With regard to the results of the instruments, on the MoCA-B, the mean score for the sample was 21.09 \pm 5.25 and the mean score on the MMSE was $24.64 \pm$ 4.08 ( $p<0.001)$. The effect size between these two means was considered average $(d=-0.755)$. There was no significant difference in performance on the tests related to sex. Table 3 shows the performance (means, standard deviations) of the MoCA-B and MMSE in relation to years of schooling of the sample and the effect size between the means for these instruments.

The ANOVA analysis showed that different schooling categories have an effect on the mean MoCA-B score $\left(F_{3,159}=22.288 ; p<0.001\right)$ and on the mean MMSE score $\left(F_{3,159}=26.959 ; p<0.001\right)$. For both instruments, performance on the instruments increased as years of schooling categories increased. Considering Cohen's classification (1988), the effect size between the instruments in relation to the group was classified as small in the sample of illiterate participants, large in the samples with from 1 to 5 years in education and from
6 to 11 years of schooling, and medium in the sample with 12 years or more of schooling.

Table 4 presents data about effect size of schooling between groups in the same instrument.

Based on this analysis, the MoCA-B had a smaller effect size of average schooling than the MMSE. There was no significant difference in the analysis of mean MoCA-B scores between illiterate participants and those with 1 to 5 years of schooling. In the MMSE, the effect size between these groups was considered large. In this instrument, the group of illiterate participants had the highest impact of effect on the means. The effect sizes observed between MoCA-B means ranged from medium to very large and the MMSE effect sizes ranged from medium to huge. ${ }^{11}$

The influence of schooling on instrument scores was confirmed by linear regression. Results for the MoCA-B show that schooling predicts $29.6 \%$ of the total score $\left(F_{1,161}=22.288 ; p<0.001\right)$. The results for the MMSE show that schooling predicts $33.71 \%$ of the total score.

With relation to the influence of age on instrument performance, linear regression showed that age predicts the total MoCA-B score in $18.03 \%\left(F_{1,161}=35.433 ; p<\right.$ $0.001)$. The MoCA-B score corresponds to 29.300-0.151 $\times$ (age in years). Age predicts $8.52 \%$ of the total MMSE score $\left(F_{1,161}=14,997 ; p<0.001\right)$. The total MMSE score corresponds to $29.024-0.081 \times$ (age in years).

Table 2 - MoCA-B component scores

\begin{tabular}{lcccc}
\hline & Mean & SD & Min & Max \\
\hline Executive function & 0.23 & 0.42 & 0.0 & 1.0 \\
Fluency & 1.13 & 0.76 & 0.0 & 6.0 \\
Orientation & 5.70 & 0.70 & 2.0 & 6.0 \\
Calculation & 1.72 & 1.18 & 0.0 & 3.0 \\
Abstraction & 1.59 & 1.15 & 0.0 & 3.0 \\
Delayed recall & 2.94 & 1.61 & 0.0 & 5.0 \\
Visuoperception & 1.95 & 1.02 & 0.0 & 3.0 \\
Naming & 3.50 & 0.76 & 0.0 & 4.0 \\
Attention 1 (concentrated) & 0.67 & 0.47 & 0.0 & 1.0 \\
Attention 2 (divided) & 1.33 & 0.93 & 0.0 & 2.0 \\
\hline
\end{tabular}

Max = maximum; Min = minimum; SD = standard deviation .

Table 3 - Sample performance on MoCA-B and MMSE, by years of schooling, and effect size between instruments

\begin{tabular}{|c|c|c|c|c|c|c|c|}
\hline & \multicolumn{3}{|c|}{ MoCA-B } & \multicolumn{2}{|c|}{ MMSE } & \multirow[b]{2}{*}{$\mathbf{p}$} & \multirow[b]{2}{*}{ d } \\
\hline & $\mathbf{n}$ & Mean & SD & Mean & SD & & \\
\hline Illiterate & 11 & 16.73 & 5.62 & 18.27 & 2.45 & $<0.001$ & 0.355 \\
\hline 1 to 5 years & 53 & 18.06 & 5.11 & 22.89 & 4.22 & $<0.001$ & 1.031 \\
\hline 6 to 11 years & 49 & 21.80 & 4.29 & 25.76 & 3.17 & $<0.001$ & 1.050 \\
\hline 12 or more years & 50 & 24.56 & 3.48 & 26.82 & 2.54 & $<0.001$ & 0.742 \\
\hline
\end{tabular}

$\mathrm{d}=$ effect size; MMSE = Mini Mental State Examination; MoCA-B = Montreal Cognitive Assessment - Basic; SD = standard deviation. 
Table 5 presents the sensitivity and specificity of the instrument according to the cutoff criteria analyzed.

With a cutoff score of $<21$, the instrument achieved $77.46 \%$ sensitivity and $72.83 \%$ specificity. Figure 1 shows the ROC curve plotted to determine the best sensitivity and specificity for MoCA-B.

Using the MoCA-B to detect cognitive impairment with a cutoff of $\leq 21$ showed better results than chance (AUC $=0.777, p<0.001$, Youden index $=0.503)$.
Table 4 - Size of the effect of schooling between groups in MoCA-B and MMSE instruments

\begin{tabular}{lll}
\hline & $\mathbf{p}$ & $\mathbf{d}$ \\
\hline $\begin{array}{l}\text { MOCA-B } \\
\text { Illiterate }\end{array}$ & & \\
6 to 11 years & 0.005 & -1.01 \\
12 or more years & $<0.001$ & -1.68 \\
& & \\
1 to 5 years & & \\
6 to 11 years & $<0.001$ & -0.79 \\
12 or more years & $<0.001$ & -1.49 \\
& & \\
6 to 11 years & & \\
12 or more years & 0.014 & -0.71 \\
& & \\
MMSE & & -1.34 \\
Illiterate & & -2.64 \\
1 to 5 years & $<0.001$ & -3.43 \\
6 to 11 years & $<0.001$ & \\
12 or more years & $<0.001$ & -0.77 \\
1 to 5 years & & -1.13 \\
6 to 11 years & & \\
12 or more years & $<0.001$ &
\end{tabular}

Table 5 - Sensitivity and specificity for each cutoff criterion

\begin{tabular}{lcc}
\hline Criterion & Sensitivity & Specificity \\
\hline$<6$ & 0 & 100 \\
$\leq 8$ & 5.63 & 100 \\
$\leq 12$ & 8.45 & 98.91 \\
$\leq 13$ & 16.9 & 97.83 \\
$\leq 14$ & 21.13 & 96.74 \\
$\leq 15$ & 30.99 & 95.65 \\
$\leq 16$ & 38.03 & 91.3 \\
$\leq 17$ & 42.25 & 84.78 \\
$\leq 18$ & 56.34 & 81.52 \\
$\leq 19$ & 57.75 & 79.35 \\
$\leq 20$ & 69.01 & 76.09 \\
$\leq 21$ & 77.46 & 72.83 \\
$\leq 22$ & 78.87 & 66.3 \\
$\leq 23$ & 84.51 & 55.43 \\
$\leq 24$ & 87.32 & 46.74 \\
$\leq 25$ & 92.96 & 34.78 \\
$\leq 26$ & 92.96 & 28.26 \\
$\leq 27$ & 95.77 & 14.13 \\
$\leq 28$ & 98.59 & 8.7 \\
$\leq 29$ & 100 & 0 \\
\hline & &
\end{tabular}

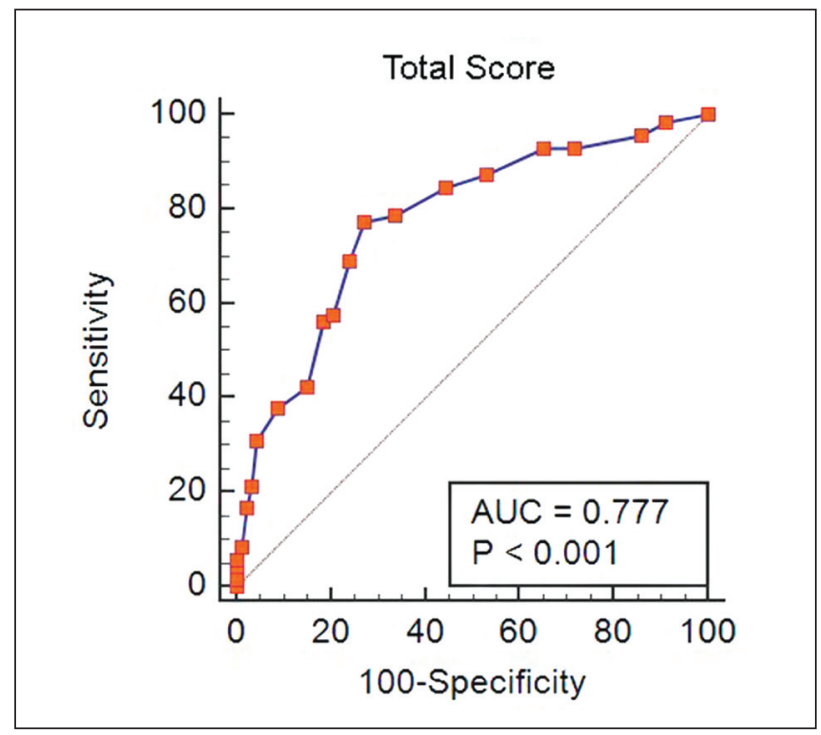

Figure 1 - ROC Curve for MoCA-B based on MMSE. 


\section{Discussion}

The aim of this study was to determine the specificity and sensitivity of the Brazilian Portuguese version of the MoCA-B in a population with Chronic Kidney Disease. The results showed that the cutoff criterion $\leq 21$ had good levels of sensitivity (77.46\%) and specificity (72.83\%). The MoCA-B had a lower effect of schooling than the MMSE for diagnosis of cognitive impairment in this population. These results corroborate previous studies in other clinical populations. ${ }^{7,12}$

The MoCA-B demonstrated reliable internal consistency (Cronbach's alpha $=0.74$ ). The cut-off point proposed by the original study was $\leq 24$ points. ${ }^{7}$ Using this criterion, we obtained sensitivity of $87.32 \%$ and specificity of $46.74 \%$. It was found that the cutoff score of $\leq 21$, proposed by this study, provides more accurate results than the original study.

Other studies of international versions that sought to identify the psychometric characteristics of the instrument proposed different cut-off points for different levels of schooling. The Chinese MoCA-B adaptation study, by Chen et al., ${ }^{8}$ proposed < 19 for the educational level group of less than 6 years (sensitivity $87.9 \%$, specificity $81.0 \%$, AUC 0.96); $<22$ for the 7 to 12 year group (sensitivity $92.9 \%$, specificity $91.2 \%$, AUC 0.949); and < 24 for the group with more than 12 years of schooling (sensitivity $89.9 \%$, specificity $81.5 \%$, AUC 0.916 ). To validate the Egyptian version of MoCA-B in the elderly population, two cutoff points were recommended for identification of cognitive impairment: < 21 considering any amount of schooling, and $<18$ taking into account only individuals with low schooling. ${ }^{9}$ Considering the results found in the analysis conducted in the present study in patients with CKD, the cut-off point of $<21$ provided the best sensitivity and specificity for identification of cognitive impairment in any of the proposed categories of schooling.

The cut-off criteria of different versions of the full MoCA have recently been reanalyzed. A metaanalysis performed in Canada, ${ }^{13}$ with full versions of the MoCA in English detected problems with sensitivity and specificity and showed that the cut-off point of 23 presented higher classification accuracy (90\%) and a better balance between false and true positive rates (Youden index $=0.79$ ). One of the few studies carried out with the Brazilian version of the full MoCA, by Sarmento, ${ }^{6}$ suggested a cut-off of 24 for MoCA, with $70 \%$ sensitivity and $63 \%$ specificity. However, the author found that this version of the instrument had low internal consistency. Recently, a study by Apolinario et al., ${ }^{14}$ proposed a detailed evaluation table for this version of the instrument in which the age and schooling of the people evaluated are considered.

The present study identified that the variable education had less impact on the total score of the MoCA-B than on the total score of the MMSE. Considering that the purpose of the instrument is to evaluate populations with low educational level, it is adequate for evaluation of the Brazilian population with CKD. Several studies suggest that schooling is low among CKD patients and it is estimated that the majority did not finish elementary school. ${ }^{15,16}$

Ardila $^{17}$ reports that the influence of educational variables on the performance of neuropsychological tests is well established, demonstrated both in individuals without pathologies and also in populations with brain damage. However, the educational effect is not linear, it represents a negatively accelerated curve, tending to a threshold, since the ceiling in neuropsychological tests is usually low. This author reports that the differences between 0 and 3 years of education are highly significant, but differences decrease as years of study increase, and the tendency is not to find differences between, for example, 12 and 15 years of schooling. A similar relationship is observed with the effect of age, although only from 50 years of age onwards. It is expected that performance is relatively homogeneous between 18 and 50 years of age.

In this study, the MoCA-B instrument showed a greater influence from age than the MMSE. It is considered that this influence does not constitute a negative factor for the instrument, since the age correlation found may reflect cognitive aging and how progressive diseases that affect the renal vascular systems over the years also affect the brain. Morillo et al. ${ }^{18}$ report that the age factor and underlying pathological conditions, such as hyperglycemia, hyperlipemia, and arterial hypertension, can result in loss of brain volume, leading to higher brain atrophy. Thus, it can be hypothesized that the MoCA-B is more effective than the MMSE for detecting the effects of aging.

Limitations of this study include the fact that the sample comprised only patients who are on hemodialysis treatment, which may be a bias when considering the entire CKD population. Although this is the treatment used by $92 \%$ of patients who undergo renal replacement therapy, ${ }^{19}$ it is a more aggressive treatment for the body and cognition of the CKD patient. ${ }^{20,21}$ Another possible limitation is the use of the MMSE as a criterion for identifying cognitive impairment. It is believed that future methodologies could include administration of more assessment tools, such as a more extensive neuropsychological battery of functions or a functional measurement scale based on informants for differentiation of cognitive impairment and dementia. It is also considered that in future research some 
criteria should be included for inclusion and exclusion of patients, such as time on treatment and biochemical markers. It would thus be possible to analyze these important variables for patients' cognition.

Despite these limitations, the study has made some significant contributions to the area. The lack of studies on the Brazilian Portuguese version of the MoCA-B instrument, especially in populations with CKD should be emphasized. The sample size was adequate for generalization of results. The establishment of a cut-off point for identification of cognitive impairment among people with CKD enables health professionals to use the instrument in an adequate manner, to assist in clinical management of the actions of those working with this population.

\section{Conclusion}

The MoCA-B has been shown to be a suitable screening instrument for evaluating the global cognition of hemodialysis patients. A cut-off point of $\leq 21$ points had the best sensitivity and specificity for detection of cognitive impairment. Considering that impairment of cognitive functions in CKD is associated with neuropsychiatric disorders, ${ }^{1}$ it is essential to understand cognitive impairment and dysfunctions in this population, incorporating predictive instruments such as this in primary care and reinforcing the role of prevention and detection of degenerative diseases. ${ }^{2}$ In addition to offering tools for primary care, the results of this study also contribute to guiding health professionals in evaluation and clinical management since, based on identification of cognitive impairment, they can improve the focus of their intervention strategies according to the patient's quality of life, delaying progression of cognitive decline.

\section{Disclosure}

No conflicts of interest declared concerning the publication of this article.

\section{References}

1. Matta SM da, Moreira JM, Kummer AM, Barbosa IG, Teixeira AL, Silva ACS. Cognitive alterations in chronic kidney disease: an update. J Bras Nefrol. 2014;36:241-5.

2. Martins IP, Maruta C, Morgado J, Loureiro C, Tavares J, Freitas $\mathrm{V}$, et al. Predictors of cognitive stability or decline during aging: A longitudinal study in primary care. Appl Neuropsychol Adult. 2018;0:1-13.

3. Foster R, Walker S, Brar R, Hiebert B, Komenda P, Rigatto C, et al. Cognitive impairment in advanced chronic kidney disease: the Canadian Frailty Observation and Interventions Trial. Am J Nephrol. 2016;473-80.

4. Ismail Z, Rajji TK, Shulman KI. Brief cognitive screening instruments: an update. Int J Geriatr Psychiatry. 2010;25:11120.

5. Nasreddine Z, Phillips N, Bédirian V, Charbonneau S, Whitehead V, Colllin I, et al. The Montreal Cognitive Assessment, MoCA: a brief screening tool for mild cognitive impairment. J Am Geriatr Soc. 2005;53:695-9.

6. Sarmento ALR. Apresentação e aplicabilidade da versão brasileira da MoCA (Montreal Cognitive Assessment) para rastreio de comprometimento cognitivo leve [dissertation]. São Paulo: Universidade Federal de São Paulo; 2009.

7. Julayanont $P$, Tangwongchai $S$, Hemrungrojn $S$, Tunvirachaisakul C, Phanthumchinda K, Hongsawat J, et al. The Montreal Cognitive Assessment - Basic: a screening tool for mild cognitive impairment in illiterate and low-educated elderly adults. J Am Geriatr Soc. 2015;63:2550-4.

8. Chen K-L, Xu Y, Chu A-Q, Ding D, Liang X-N, Nasreddine ZS, et al. Validation of the Chinese version of Montreal Cognitive Assessment Basic for screening mild cognitive impairment. J Am Geriatr Soc. 2016;64:e285-90.

9. Saleh AA, Alkholy RSAEHA, Khalaf OO, Sabry NA, Amer H, ElJaafary $S$, et al. Validation of Montreal Cognitive AssessmentBasic in a sample of elderly Egyptians with neurocognitive disorders. Aging Ment Heal. 2019;23:551-7.

10. Duncan BB, Schmidt MI, Giugliani ERJ, Duncan MS, Giugliani C. Medicina ambulatorial: condutas de atenção primária baseadas em evidências. 4th ed. Porto Alegre: Artmed; 2013.

11. Sawilowsky SS. New effect size rules of thumb. J Mod Appl Stat Methods. 2009;8:597-9.

12. Rambe AS, Fitri FI, Utara US. Correlation between the Montreal Cognitive Assessment- Indonesian version (Moca-INA) and the Mini-Mental State Examination (MMSE) in elderly. J Med Sci. 2017;5:915-9.

13. Carson N, Leach L, Murphy KJ. A re-examination of Montreal Cognitive Assessment (MoCA) cutoff scores. Int J Geriatr Psychiatry. 2017;33:379-88.

14. Apolinario D, Pegoraro F, Funchal M, Sassaki E, Vitoria A, Pedrini $A$, et al. Normative data for the Montreal Cognitive Assessment ( MoCA ) and the Memory Index Score (MoCA $\square$ MIS) in Brazil: adjusting the nonlinear effects of education with fractional polynomials. Int J Geriatr Psychiatry. 2018;33:893-9.

15. Cherchiglia ML, Machado EL, Szuster DAC, Andrade EIG, Acúrcio FA, Caiaffa WT, et al. Perfil epidemiológico dos pacientes em terapia renal substitutiva no Brasil, 2000-2004. Rev Saude Publica. 2010;44:639-49.

16. Oliveira APB, Schmidt DB, Amatneeks TM, Santos JC dos, Cavallet LHR, Michel RB. Quality of life in hemodialysis patients and the relationship with mortality, hospitalizations and poor treatment adherence. J Bras Nefrol. 2016;38:411-20.

17. Ardila A. A Note of caution: normative neuropsychological test performance: effects of age, education, gender and ethnicity: a comment on Saykin et al. (1995). Appl Neuropsychol. 1998;5:513.

18. Morillo LS, Brucki SMD, Nitrini R. Modificações neurobiológicas e cognição no envelhecimento. In: Miotto EC, Lucia MCS, Scaff M, editors. Neuropsicologia Clínica. São Paulo: Roca; 2015. p. 22741.

19. Sesso RC, Lopes AA, Thomé FS, Lugon JR, Martins CT. Brazilian chronic dialysis survey 2016. J Bras Nefrol. 2017;39:261-6.

20. Drew DA, Weiner DE. Cognitive impairment in chronic kidney disease: keep vascular disease in mind. Kidney Int. 2014;85:5057.

21. Schneider SM, Malecki AK, Müller K, Schönfeld R, Girndt M, Mohr $P$, et al. Effect of a single dialysis session on cognitive function in CKD5D patients: a prospective clinical study. Nephrol Dial Transplant. 2015;30:1551-9.

\section{Correspondence:}

Thaís Malucelli Amatneeks

Fundação Pró-Renal, Universidade Federal do Paraná

Programa de Pós-Graduação em Psicologia

Av. Vicente Machado, 2190

CEP 80440-020 - Curitiba, PR - Brazil

Tel.: +55 (41) 99845-9030

E-mail: Thais.malucelli@gmail.com 